\title{
Motivations for Engaging in Radio Phone-in Programmes Among Radio Users in Osogbo
}

\author{
Kolade Apata $^{1^{*}} \quad$ Lukuman Azeez ${ }^{2}$ Ph.D \\ 1.Osun State Broadcasting Corporation, Oshogbo, Osun State, Nigeria \\ 2.Department of Mass Communication, University of Ilorin, Nigeria
}

\begin{abstract}
This study examined motivations for engaging in Osun state radio phone in programmes among radio users in Southwest Nigeria. The thrust of the study is to bridge the gap in knowledge by examining motivations for participation in phone-in programmes on Osun state radio and investigate any variations in the radio listeners' participation in phone-in programmes on Osun state radio in terms of age. To achieve this and in line with the Uses and Gratification Theory upon which the study is premised, Survey and in-depth interview methods were used with a sample size of 384 respondents which were selected randomly for the survey while 5 presenters of the selected phone-in programmes were interviewed and analysed. The findings indicated among other things that the majority of the respondents often participate in phone-in programmes on Osun state radio when the topic of discussion interest them; due to programmes' format, when a favourite presenter was anchoring.
\end{abstract}

Keywords: Motivations, Phone-ins, Radio, Users

DOI: $10.7176 / \mathrm{NMMC} / 81-05$

Publication date:June $30^{\text {th }} 2019$

\section{Introduction}

Gone are the days when radio is literarily described as "Asoromagbesi" a parlance in Yoruba (South West Nigeria) meaning a device that talk and never receive instant feedback. "Traditional media such as radio have to certain extent incorporate audience participation into their programming through phone-in programmes which has provided robust platform for members of the public to participate in live radio programme and confer on them a celebrity status" (Wallace, 2013).

However, Radio from inception played important role in development communication as a result of its advantage of reaching large number of people from different sections of the society. The device is undoubtedly regarded as a lifeline through its programmes dissemination that sometimes broadens the knowledge of the listeners and makes them more intellectually sound as well as morally upright. Thus, the distinct function of radio in the advancement of rural areas cannot be overstated as radio stations are described as a vector of education, awareness raising, knowledge acquisition and tool for influencing the dynamics of social relations as well as addressing gender inequality (Adamou, Fatouma \& Elstraeten, 2014).

Much as radio is recognised as a powerful medium because of its audience reach, accessibility and greater companion to the teeming listeners as well as forum for audience to interact with one another more easily than television viewers or newspaper readers, this study is set to examine the rationale behind motivations for engaging in Osun state radio phone-in programmes among radio users in Osogbo. In order words the study aims answering questions whether there are variations in their participation in terms of age of the participants.

\subsection{Statement of Problem}

Traditional media such as radio has no doubt enhanced its operation by advancing the concept of audience participatory through the integration of phone-in programmes into their programming. Consequently, new media including mobile technology has been helpful in this regard as phone-in programmes on radio has undoubtedly reinforced the normative responsibility of the broadcast media and served as a platform for people to contribute to public discourse on issues and providing solutions to such contending issues. However, various related studies have been conducted on the importance and role of phone-in programmes to understand the trend researches have been done on the issue and these research works have provided a reliable body of knowledge on the subject. For instance, in BBC world service (2009) Vietnamese youth carried out research on the importance of phone-in programmes in Vietnam using a programme tagged 60 minutes you and me and reported that a live phone-in radio programming is highly popular and effective in stimulating discussion, exchanging ideas and supporting behaviour change among youths. Also, in Wallace (2013) another study tagged the role of radio and mobile phones in conflict situations: the case of the 2008 Zimbabwe elections and xenophobic attacks in Cape Town was examined and as the researcher considered the role that radio and information communication technologies (ICT) especially mobile phones played in the lives of citizens, he concluded that 'new' media is being appropriated by the 'old' media to enhance both news-making and participatory cultures among audiences. In Nigeria, Eze (2014) in her research work on impact of "'ka oh malu" radio Nigeria Enugu phone-in programme on residents of Enugu urban, discovered that phone-in programme help in enhancing audience participation, create source and avenue for 
continuous interaction between source and receiver as well as help in assessing programme performance.

However, due to limited studies base on the subject, none of these research works have delved substantially on the issue especially in investigating the rationale behind the participation of radio listeners in programme production on Osun state radio and motivations for engaging in phone-in programmes. To this end, this study bridges the gap in knowledge by examining motivations for engaging in phone-in programmes on Osun State radio among radio users in Osogbo, Southwest, Nigeria and investigate any variations in the radio listeners' participations in phone-in programmes on Osun state radio in terms of age.

\subsection{Objectives of the study}

The general objective is to determine radio listeners' participation in programme production and their motivations for participating in phone-ins on Osun state radio.

The specific objectives are:

1. To determine the extent to which listeners participate in phone-in programmes

2. To examine the type of phone-in programmes listeners have preference for on Osun State radio.

3. To examine the motivations for participating in phone-in programmes.

4. To examine any variation in their participation in terms of age.

5. To determine how phone-ins has been helpful to programme production in Osun state radio.

\subsection{Research Questions}

The study proffers answers to the following research questions:

1. To what extent do listeners participate in phone-ins on Osun state radio?

2. What type of phone-in programmes do they have preference for?

3. What are the motivations for participating in phone-in programmes on Osun state radio?

4. What are the variations in their participation and engaging in phone-ins in terms of age?

5. Do phone-ins assist programme production on Osun state radio?

\section{Literature Review}

\subsection{Nature of Radio}

Radio just like television is a tool that can be used to bring about positive attitudinal change in the audience. Radio helps to achieve development, both in the rural and urban areas, as issues of development are aired to the audience in the form of various programmes and individuals are exposed to happenings in and around their society through listening to programmes (Asemah, Anum \& Edegoh, 2013). From the view point of Tafida (1986), cited in Asemah (2011), radio is so powerful; it brings political, economic and social news to any community or any group of communities. The key role assigned to radio is to inform, educate, enlighten and entertain (Wigwe, 1988). AsekunOlarinmoye (2013) explained that radio is the single most important media equipment, because it reaches larger audiences anywhere in the world. This is so because it is fast, as events occur they are related to the potential audience. Kuewumi (2009) also added that radio has the ability to reach millions of people simultaneously, yet it speaks to an individual personally. The listener feels a great companion in his radio especially when it is discussing something so relevant, sensible or personal to him. It is amazing how radio can reach a large number of people and it's still so personal to each individual who listens.

Asemah (2011) opined that of all the mass media generally available to Africans, radio is the most widespread, accessible and because of its special qualities, radio can be a major force in bringing about development that is to any quantitative and qualitative improvements in the lives of the people. He stated further that the information dispersing and the enlightenment role of radio is the commonest of its functions and this disseminating function covers information to people's alertness to health, agriculture, education, economy as well as politics.

Radio is easily accessible and affordable, easily understood and accepted. It does not demand any complexity in broadcasting or listening. It can be used or listened to anytime and anywhere. The unique nature of radio is such that it appears to be one medium of mass communication that everyone can easily identify with (Asemah et al, 2013). Nwuneli, cited in Asemah (2011) in his own contribution on the role of radio, said it has brought stimulus into the house, brings about competitions within families, thereby, grooming people who will contribute positively to the process of development.

\subsection{Radio Listeners}

Chioma, Solo-Anaeto \& Jegede (2015) declared that radio broadcast audience are referred to as listeners as broadcast audiences are individuals for which radio programs as well as messages are planned, produced and delivered, consequently they are the reason for the existence and sustenance of every broadcast organization across the globe. Chioma et. al. (2015) further captured this thought by saying it is largely upon the listener's ability to imagine matters of fact that radio's distinctive and much-vaunted sense of personal companionship seems to depend. Therefore, it is through the voice of the on-air personnel that radio listeners create an imagination. Crissell 
(1994) revealed the free and participatory opportunities offered by radio stations as he noted that figures of those who listen to radio continue to increase thus indicating an increasing affinity for content of radio programmes.

Ajaegbu, Akintayo \& Akinjiyan (2015) submitted that listeners use and relate to radio in very different ways compared to other media as he explained that listeners use radio for various reasons one of which is for emotional support, to keep their spirits up through programmes and the result will determine to a large extent the attitude listeners would have to programmes. Ismaila (2013) wrote that majority of the population listen to radio regularly especially adults and young ones and many listeners are loyal to their favourite stations and are often tuned for long periods to a station adding that listeners use and relate to radio in a very different way to other media.

Padmakumar (2015) posited that radio listeners could be grouped into two types: active and passive ones. The active listeners according to him show a high level of involvement with the radio station by demonstrating their loyalty towards the station, by actively engaging themselves with the station's activities such as listening to the radio station for a longer duration on a daily basis, showing awareness of the programmes of the station, keeping in touch with the station constantly by calling and texting the station frequently keeping track of all the events and contests conducted by the radio stations and keenly participate in those events.

\subsection{Conceptualization of Radio Phone-In Programmes}

In this age of technological development, phone-in is the most important programme format as it is called interactive programming where listeners and presenters exchange views, involve in conversation which goes on air instantly. The listener has the satisfaction that his voice is being listened to and replied immediately as other listeners also listen to him while such presentations need advance publicity so that the listeners could get ready to air their grievances, queries or requests. They dial up the announced telephone number at a stipulated time and get their problems discussed with experts in the studio. Initially this format was introduced for playing the listeners' request based film songs. Now it is being used for health related programmes, rural broadcasts, complaints against the government/administrative machinery etc (Beaman, 2006).

However, with modern advances in information and communication innovation such as satellite technology, telephony and the Internet, Alabi (2014) posited that it has become possible for the electronic media to know their audience spread, to interact, and to receive instant and delayed feedbacks from them. Pool (1983) cited in Willems (2013) said new media such as internet and mobile phones arguably have made possible new forms of participatory media culture. He stated further that conventional media such as radio and television have to a certain extent made attempts to incorporate audience participation into their programming, through 'new media' such as the internet and mobile phones which has the capability to facilitate contributions from members of the public to the democratic participatory mode of governance.

According to Wallace (2013), radio phone-in programme format is undoubtedly considered an area for participation as part of the public sphere a concept develop by a communication scholar Jurgen Habermas which generally relates to a media system that provides accessible space for the articulation of 'rational-critical' discussion and debate by the citizenry. However, Eze (2014) opined that phone in programme is a format in which listeners are invited to air their views comments, opinion through telephone, usually in respect of a specific topic for discussion as the presenter made the line open for interested listener to share his/her views using mobile phones. He amplified this thought by saying that the participatory nature of phone-in programme is expected to confer on an individual radio listener a sense of belonging and not make him an inactive receiver of information and ideas passed across by the radio.

\subsection{Theoretical Framework}

The uses and gratification theory is relevant to this study because the theory attempts to explain the uses and functions of the media for individuals, groups, and society in general. Uses and gratifications theory arise from a line of work that focuses on the interdependent relationships among the media system, the larger social system, and media audiences. Together, these theories predict that audiences rely on media to gratify specific needs (participation) and in the process develop certain dependencies (motivations) on the media. The more an individual depends on a specific medium to fulfill needs, the more important that media will become to that person. This can, in turn, lead to different patterns of media exposure and use. Ultimately, this can lead to cognitive, affective, and behaviour effects of media use (engaging).

The theorists say that a media user seeks out a media source that best fulfills the needs of the user. Consequently, Radio users participate in phone-in programmes to gratify their desires and in so doing have influenced Osun state radio: because the station (Osun state radio) would in turn begin to enhance the content of its phone-in programme so as to improve the participation of its listeners. This support the fact that media use is motivated by needs and goals that are defined by audience members themselves (Blumler \& Katz, 1974; Owuamalam, 2007). 


\section{Methodology}

Due to the design, the researcher adopts survey method in the quantitative approach. Since this study is radio audience research requiring participation, opinions, attitudes and motivations for engaging in phone-ins among Radio users in Oshogbo Southwest Nigeria, the survey method was considered suitable for the work because this method enable the researcher to gather data relating to the personal opinions, ideas and perception of respondents. The phone-in programs selected are Eroya, Happy day, Lunch Break, Platform and Ela loro based on their popularity and volume of traffic during phone-in. Also, in-depth interview was considered as another research method in this study because it facilitates the conduct of intensive individual interview to explore the perspectives of the respondents, that is the presenters of the 5 phone-in programmes on how phone-in programmes has been helpful to programme production on Osun state radio Southwest Nigeria. Asika (2006) explained that the population of a study is a made up of all consumable elements, subject or observations relating to a particular phenomenon of interest to the research. The population of the study under survey method were the participants of phone-in programmes on Osun state Radio resident in Osogbo Southwest Nigeria while the population of study for the in-depth interview method were the presenters of phone-in programmes on Osun state radio in the Southwest part of Nigeria. However, according to the National Population Commission (2015) the population of Osogbo as at year 2015 is estimated to be 649,600. From this population Osun State radio has an estimated shared population of 480,000 (Centre for Distance Learning, OAU, Ile-Ife, 2009) where the sample size was drawn. Also, the sample size for this study using survey method were three hundred and eighty four (384) respondents according to Krejcie \& Morgan table (1970) using Confidence Level of 95\% and Margin of Error of 5\%. While the sample size for this study using in-depth interview method were five (5) presenters of the selected phone-in programmes on Osun state radio in Osogbo Southwest Nigeria. This study adopts Simple Random Sampling Technique under Survey method; it entails random selection of seventy-five (75) phone-in callers from the sample frame for each of the five phone-in programmes that were analysed. The sample frame consisted of the names and contact of all the regular callers into the programme that were kept by the presenters of the selected phone-in programmes and they were released for the study. To this end, using the sample frame, participants of the selected phone-in programmes were contacted on the social media platform that had been created by the presenters and converged at a secluded place where questionnaire were distributed to them. In addition, the sample size for this study using in-depth interview method comprised of five (5) presenters of the five selected phone-in programmes on Osun state radio and purposive sampling technique was employed to gather data from the respondents using in-depth interview guide that focused on the experiences of the presenters particularly benefits of the selected phone-in programmes to listeners and to the station to determine how phone-ins has been helpful to programme production on Osun state radio.

\section{Findings and Discussion}

The data generated for the study are discussed under the research questions they address. The data were analysed using SPSS.

\section{Analysis Based on Research Questions}

Research Q 1: To what extent do listeners participate in phone-ins on Osun state radio? Table 1 provides the result of respondent's level of participation in phone-in programmes on Osun state radio.

Table 1: Respondents Level of Participation

\begin{tabular}{lll}
\hline Category & Frequency & Percentage \\
\hline Respondents that participate in phone-in Programmes & 82.6 \\
Yes & 304 & 17.4 \\
No & 64 & $\mathbf{1 0 0}$ \\
Total & $\mathbf{n = 3 6 8}$ & 3.2 \\
Frequency Level of Participation & & 78.0 \\
Everyday & 12 & 12.9 \\
Frequently & 292 & 5.9 \\
Occasionally & 48 & $\mathbf{1 0 0}$ \\
Not at all & 22 & $\mathbf{1 0 0}$ \\
Total & $\mathbf{n = 3 7 2}$ & \\
\hline
\end{tabular}

(Source: Field survey, 2018)

The table revealed that $82.6 \%$ participated in phone-in programmes on Osun state radio while $17.4 \%$ did not participate in phone-in. The table revealed that $78.0 \%$ listened to Osun state radio frequently, $3.2 \%$ listened to programmes on Osun state radio every day, $12.9 \%$ listened to programmes on Osun state radio occasionally, while $5.9 \%$ did not listen to programmes on Osun state radio at all. This means that respondents' level of followership of the phone-in programme is high and thus, can determine their level of participation to be high also. 
R.Q 2: What type of phone-in programmes do they have preference for?

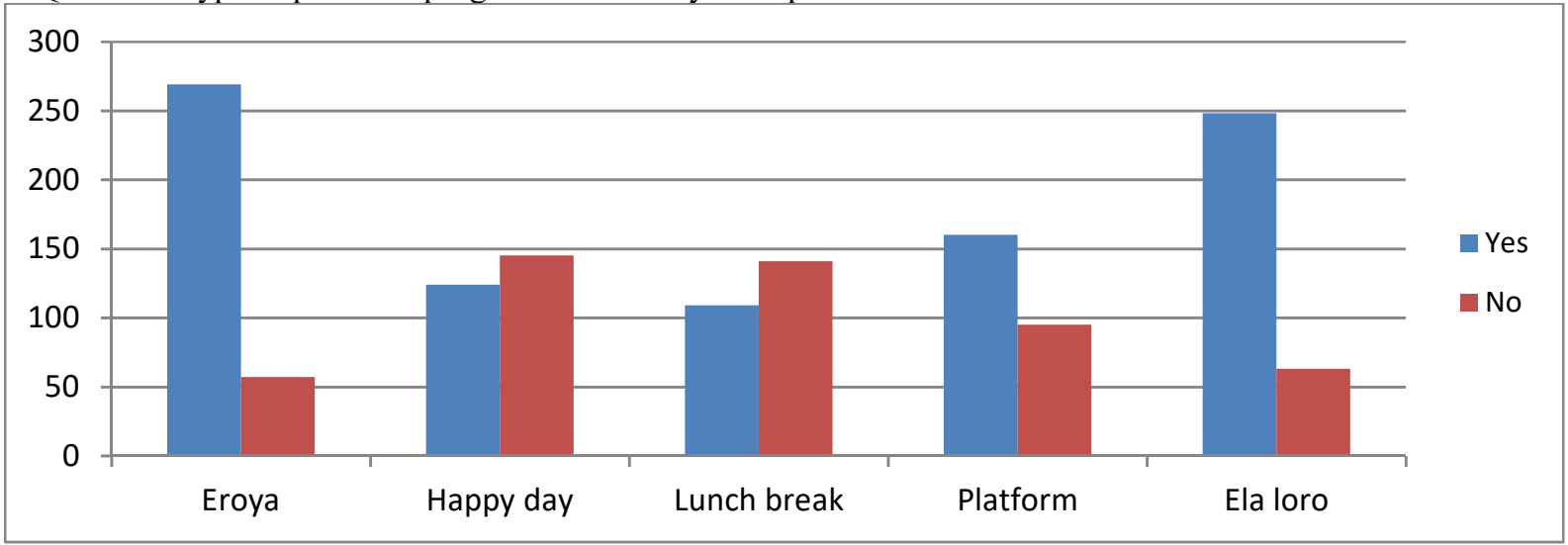

Figure 1: Preference for phone-in programmes by the respondents

In Figure 1, data revealed that Eroya yoruba magazine phone-in programme is the most preferred phone-in programme on Osun state radio with $n=269$ representing $(82.5 \%)$ followed by Ela loro a yoruba audience personality programme with $n=248(79.7 \%)$. Also, $n=160$ representing $(62.7 \%)$ preferred Platform a current affairs personality programme, while $n=124(46.1 \%)$ chose Happy Day programme an entertainment programme and $\mathrm{n}=109(43.6 \%)$ preferred Lunch break also an entertainment programme. Therefore, the majority of the participants in phone-in programmes on Osun state radio preferred mostly Eroya, a Yoruba magazine programme and Elaloro, a Yoruba interview personality phone-in programmes respectively.

R.Q 3: What are the motivations for Participating in phone-in programmes on Osun state radio?

Table 2: Motivations for Participating in Phone-In Programmes

Level of Agreement Percentage* (\%)

\begin{tabular}{|c|c|c|c|c|c|c|c|}
\hline Motivations & $\overline{1}$ & 2 & 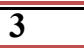 & 4 & $\overline{5}$ & $\overline{\mathbf{M}}$ & S.D \\
\hline $\begin{array}{l}\text { I am motivated to engage in phone-ins because of the } \\
\text { style of presentation }\end{array}$ & 1.4 & 2.2 & 5.3 & 26.1 & 65.0 & 4.47 & 0.87 \\
\hline $\begin{array}{l}\text { I am motivated to engage in phone-ins because of the } \\
\text { choice of words of the presenter }\end{array}$ & 0.8 & 0.3 & 4.2 & 61.5 & 17.2 & 4.07 & 0.59 \\
\hline $\begin{array}{l}\text { I am motivated to engage in phone-ins because of the } \\
\text { personality of the presenter }\end{array}$ & 3.6 & 2.0 & 10.1 & 27.4 & 56.9 & 4.30 & 1.01 \\
\hline $\begin{array}{l}\text { I am motivated to engage in phone-ins because of the } \\
\text { topic of discuss }\end{array}$ & 1.2 & 3.2 & 4.0 & 77.5 & 13.3 & 4.16 & 0.75 \\
\hline $\begin{array}{l}\text { I am motivated to engage in phone-ins because of the } \\
\text { language of presentation }\end{array}$ & 2.8 & 1.6 & 4.8 & 23.0 & 67.6 & 4.50 & 0.91 \\
\hline $\begin{array}{l}\text { I am motivated to engage in phone-ins because of the } \\
\text { age of the target audience }\end{array}$ & 4.0 & 4.9 & 10.5 & 67.6 & 13.0 & 3.95 & 2.71 \\
\hline I am motivated to contribute to political issues & 4.1 & 7.3 & 5.3 & 17.5 & 65.9 & 4.33 & 1.13 \\
\hline $\begin{array}{l}\text { I am motivated to engage in phone-ins because of the } \\
\text { popularity of the programme }\end{array}$ & 1.6 & 7.3 & 11.4 & 66.3 & 13.4 & 3.81 & 0.84 \\
\hline I am motivated to participate in the public sphere & 4.9 & 3.3 & 8.2 & 18.0 & 65.0 & 4.36 & 1.09 \\
\hline Total & & & & & & 4.22 & 1.1 \\
\hline
\end{tabular}

(Source: Field survey, 2018)

Note: 2.5 is the cut-off point between Agreement\& disagreement on this table; Strongly Agree: 5, Agree: 4, Neutral: 3, Disagree: 2, Strongly Disagree: 1

Going by the above data presented, the result showed that a majority of the respondents are motivated to participate in phone-in programmes on Osun state radio. Overall, the information gathered in table 2 shows that respondents strongly agreed that they are motivated to participate in phone-in programmes because of some reasons $($ Mean $=4.22$, Standard Deviation $=1.1)$. 
R.Q 4: What are the variations in their participation in terms of age?

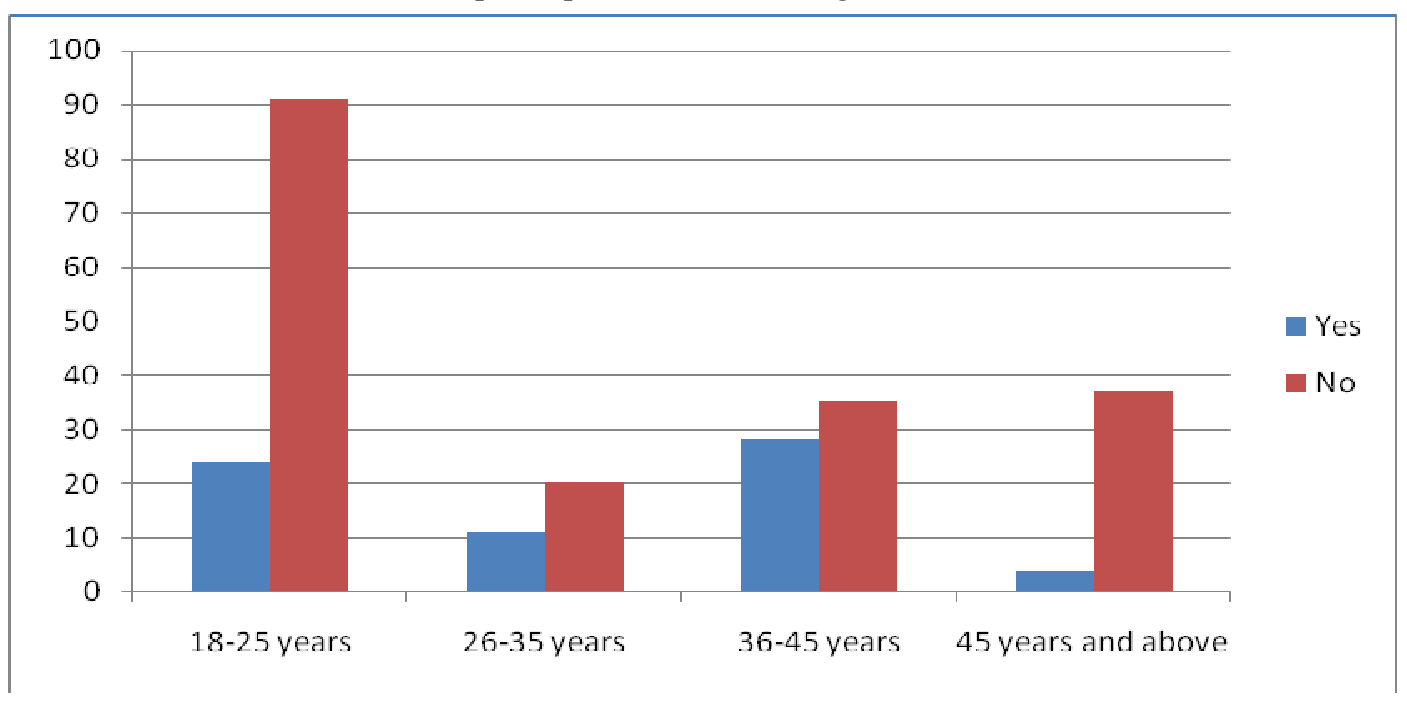

(Source: Field survey, 2017)

Figure 2 above shows the graphical representation of respondents' Participation in phone-ins targeted to their age group only.

Data from Figure 2 revealed the age of the respondents and their disposition to phone-in programmes targeted at their age group only. $79.1 \%$ in age $18-25$ years indicated that age is not a determinant for their participation in phone-ins while $20.9 \%$ ) recorded that they participate in phone-in programmes targeted at their age group. Also, $64.5 \%$ of the participants within the age 26-35 reported that their participation in phone-in programmes on Osun state radio is not defined by the age of the targeted audience. Similarly, respondents within the age group 36-45 also indicated that their participation in phone-in programme is not determined by the age of the targeted audience with $55.6 \%$ of the respondents revealed this while $44.4 \%$ chose that their participation in phone-ins is determined by the age of the targeted audience. Furthermore, same was recorded in the age group 46 and above as $90.2 \%$ indicated that their participation is not defined by the age of the targeted audience. Therefore, it was revealed that majority of the participants from different age group did not participate in phone-in programmes on Osun state radio targeted at their age group only.

Research Question 5: Do phone-ins assist programme production on Osun state radio?

Interview guide was used to elicit responses from the presenters of five selected phone-in programmes. However, data gathered from the in-depth interview were analysed using interpretative analysis method.

Findings on the experiences of the presenters particularly on the benefits of phone-in programmes to listeners on Osun state radio indicated that phone-in programmes on Osun state radio is more beneficial to the listeners as it gave them a sense of belonging.

This is reflected in the response of the first respondent:

the phone-in programmes enabled average listener to be heard speaking on radio, unlike other programme format and they do so sometimes by actively engaging in phone-ins as a way of boosting their ego or to attain some level of popularity and this invariably reflected on the number of participants on the programme who struggle to get through week-in-week out.

Also respondent two while corroborating the benefit of the phone-in programmes to the prospective listeners posited that "phone-in programme is a grass root one which enables different categories of people to partake". Furthermore, respondent three noted that:

My phone-in programme is no doubt a listeners' delight as professionals are always invited to discuss on issues that involve intellectualism while listeners are usually giving the leeway to pour out their minds and offer contributions that will add to the development of the polity.

These submissions by the respondents are indications that the selected phone-in programmes are beneficial to the listeners because listeners, prospective audience especially opinion leaders, public affairs analysts and commentators contributed meaningfully to the issue at stake as it affect their socio political and economic life and in turn gave feedback to the presenters in form of advice on the best way to improve more on the programme presentation.

Moreover, because of the topical issues that usually forms the crux of the discussion this has undoubtedly provided a space for intellectual discussion, forum for robust debate on any issues of public interest.

Thus, findings from the responses of the respondents on the benefits of phone-in programmes to listeners indicated that phone-in programmes on Osun state radio has provided a veritable forum for the participants to 
express their views thus giving voice to the voiceless, afford the prospective participants the opportunity to respond, comment or react on issues of public interest.

However, exploring the responses of the respondents (the presenter) on the benefit of phone-in programmes to them they observed that feedback from the participants usually assist in enhancing and developing the content of the programme, the response of one of the respondents support this by stating "the contributions of the listeners has enabled me to research more on issues of national interest"

Another presenter also said "when listeners call and bare their minds, it provides a huge opportunity of feedback into the minds of listeners to comment on the programme".

Furthermore, some of the presenters pointed out that the phone-in programmes have enhanced their personalities by noting that "people often rate the programme and the presenter based on the popularity of the programme, one has been identified as the symbol of excellence. I am seeing by many as a presenter that has carved a niche for himself through the programme". Also, another respondent in the affirmation stated that "listeners' contributions have enhanced my personality and credibility as I have received series of awards, accolades from non-governmental organisations as well as corporate organisations as people often referred to me as baba Elaloro" (Grand Master of Elaloro programme).

Thus, findings from the presenters revealed that the phone-in programmes on Osun state radio is beneficial to them as it contributed meaningfully in enhancing their programmes content through the feedback of the participants and conferring a credible and a popular status on the presenters.

Also, when asked on the benefit of phone-in programme to the station, some of the respondents in their responses revealed that because their phone-in programmes allow participants in their contributions to assess, appraise and criticize policies and programmes of government in power for the overall well-being of the nation, this has conferred a credible status on the station by the participants and endorsing it as well as the authentic voice of the people. The response of the presenters supports this as they affirmed that "almost $90 \%$ of listeners tune-in to the station each time the programme is on air while some have even requested the management to increase the duration". This assertion was corroborated by another presenter of a phone-in programme as he revealed that "my phone-in programme reflects the strength of listenership and allows diverse opinions even when they are critical since it is not censored, it allows the audience unfettered access".

Moreover, another phone-in programme presenter in his revelation on the benefit of his programme to the station submitted that his programme has contributed in no small measure in enhancing and improving the level of acceptability of Osun state radio. As he stated

"it serves as a platform for people to air their views and participate in democratic governance and thereby conferred on it the status of an arbitrator".

In conclusion, it could be deduced from the in-depth interview that phone-in programmes on Osun state radio is no doubt beneficial to the listeners based on the experiences of the presenters as they stated in their responses that the five selected phone-programmes focused on informing, educating and permitting debates on any choosing topic of public interest without any form of impediments and they were preferred by the participants because of the current topical issues that form the crux of the discussion which has no doubt provided a space for intellectual discussion, forum for robust debate on any issues of public interest by the listeners.

Also, feedback from the listeners on the phone-in programmes has contributed meaningfully to programmes production as feedback add effectively and efficiently to programme production in form of advice on the best way to improve more on the presentation, the type of topic to be treated in the next edition among others.

\section{Conclusion}

Alabi (2014) posited that phone-in programmes have made it possible for the electronic media to know their audience spread which are the reasons why some scholars studied it. This study as well explored the rationale behind radio listeners' participation in programme production on Osun state radio resident in Osogbo and their motivations for engaging in phone-ins.

Consequently, the theory used justified with evidence that the respondents were able to relate some issues raised in the questionnaire to the issues in the selected phone-in programmes due to their exposure to it and gave a justification that the participants chose the phone-in programme they intend to participate in due to the gratification they intend to derive in it. This corroborates the significance and importance of the uses and gratification approach to gain understanding of motivations for participation in phone-in programmes as well as the abundant of mobile phones which have no doubt increased the potential of radio as a medium of mass communication. Obviously, this has showcased the potentiality in the participatory communication to reinforce the normative responsibility of the media of being accountable to the yearnings and aspiration of the people.

Also, it is crystal clear from the study that media audiences are often motivated to listen, view or participate in media programmes by certain factors arising from the benefits accruable from their efforts. That is why the term 'uses' has revealed that participants on phone-in programmes are active contributors and their views go a long way to redefining the course of such programmes. 
This is a strong indication that radio phone-in programmes enabled radio listeners' access to experts, people in position of authorities and political leaders while participating in phone-in programmes and providing a platform for democratised debate and the engagement of the general public without restriction.

\section{Recommendations}

Radio stations should make effective use of phone-in programmes as a means of enhancing their reach and determining audience spread. Osun state radio should be more strategic in developing phone-in programmes in such a way that will be listeners delight and captivating as this will make the station more acceptable to its audience. Radio stations should produce more of phone-in programmes in people's native language with rich cultural content as this will bring about more active participation to serve the need of the audience. This is line with this research finding which reveal Eroya and Elaloro as the most preferred phone-in programmes on Osun state radio.

Producers of phone-in programmes should note that ensuring effective programme production, feedback mechanism should be given consideration as it provide a template for producers on the best approach in determining and designing phone-in programmes.

\section{References}

Adamou, M., Fatouma, D.S., \& Elstraeten, A.V. (2014). Guidelines for the production of gender responsive radio broadcasts. Food and Agriculture Organization of the United Nations. Retrieved March 4, 2018 from www.fao.org/3/a-aq230e.pdf

Ajaegbu, O.O., Akintayo, B.J., \&Akinjiyan, M.M. (2015).Radio Listening Habits among University Students and Their Attitude towards Programmes.Research on Humanities and Social Sciences, ISSN (Paper) 2224-5766 ISSN (Online) 2225-0484 (Online), Vol.5, No.12, 2015.

Alabi, O.F. (2014). Effects of Audience Feedback on Radio and Television Programmes in Lagos State, Nigeria. Journal of Language and Communication, Vol. 1 (2), pp 38-46.

Asekun-Olarinmoye, O. S. (2013). Media categories [lecture note]. Retrieved from Unpublished lecture note: Introduction to Educational Broadcasting.

Asemah, E.S .(2011). Mass Media in the contemporary Society. Jos: University Press.

Asemah, E.S., Anum, V., \& Edegoh, L.O. (2013).Radio as a Tool for Rural Development in Nigeria: Prospects and Challenges. An International Journal of Arts and HumanitiesBahir Dar, Ethiopia Vol. 2 (1), S/No 5, February, 2013:17-35.

Asika, N. (2006). Research Methodology in Behavioral Sciences. Lagos: Longman Publishing Limited Banks and Other Financial Institutions Act 1991.

BBC World Service Trust, (2009). Annual Review 2009/2010: A decade of transforming lives through Media. Retrieved from www.bbcworldservicetrust.org

Beaman, J. (2006). Programme making for radio. New York: Routledge Publishers.

Blumler J.G., \& Katz, E. (1974). The uses of mass communications: Current perspectives on gratifications research. Beverly Hills, CA: Sage.

Centre for Distance Learning, Obafemi Awolowo University, Ile-Ife, Nigeria (2009). Evaluation of coverage, reception and Utility of Osun State Broadcasting Corporation services in selected states in Nigeria. An unpublished research work.

Chioma, P.E., Solo-Anaeto, M., \& Jegede, O.O. (2015). An Evaluation of Radio Audience Satisfaction with Programming on Inspiration 92.3 FM, Lagos.International Journal of Research in Humanities and Social Studies, Volume 2 (12), December 2015, PP 99-106.

Crissell, A. (1994). Understanding Radio.(2nd ed.). Routledge London \& New York: Taylor \& Francis Group.

Eze, C.S. (2014). Impact of "kaohamalu" Radio Nigeria, Enugu phone in programme on residents of Enugu urban. Retrieved from pubs.caritasuni.edu.ng/download.php?...2014\%20Projects/...phone_in_p...

Ismaila, D.M. (2013). Youth Radio Listening Habits and Station Preferences in Nigeria. Lagos: John West Publications Limited.

Krejcie, R.V., \& Morgan, D.W. (1970). Determining Sample Size for Research Activities. Educational and Psychological Measurement, Volume 30, pp 607-610.

Kuewumi, J.B. (2009). Radio: How it Impacts the Listener Personally. Babcock University Mass Communication Journal, 2(1), 138-149.

National Population Commission (NPC), (2015). Nigeria and ICF International. Demographic and Health Survey 2013. Abuja, Nigeria, and Rockville, Maryland, USA.

Owuamalam, E.O. (2007). Radio -TV Production, Owerri: Image and Slogans Consultants Ltd.

Padmakumar, K. (2015). Understanding the Passive Listeners of Fm Radio Stations in South India. International Conference on Communication, Media, Technology and Design, 16 - 18 May 2015 Dubai - United Arab Emirates.

Wallace, C. (2013). The Role of Radio and Mobile Phones in Conflict Situations; The Case of the 2008 Zimbabwe 
Elections and Xenophobic Attacks in Cape Town. Nokoko Institute of African Studies Carleton University (Ottawa, Canada)

Wigwe, S.I.J. (1988). The Media and Integrated Rural Development, Damatob, J (Ed). Mass Communication in Africa: A Book of Reading. Enugu: Delta Press.

Willems, W. (2013). Participation - in what? Radio, convergence and the corporate logic of audience input through new media in Zambia. Telematics and Informatics, 30 (3), pp. 223-231. ISSN 0736-5853 DOI: 10.1016/j.tele.2012.02.006 